\title{
First-Line Therapy for Immune Thrombocytopenia
}

\author{
Siraj Mithoowani ${ }^{1}$ Donald M. Arnold ${ }^{1,2,3}$ \\ ${ }^{1}$ Department of Medicine, McMaster University, Hamilton, Ontario, Canada \\ ${ }^{2}$ McMaster Centre for Transfusion Research, Hamilton, Ontario, Canada \\ ${ }^{3}$ Canadian Blood Services, Hamilton, Ontario, Canada \\ Hämostaseologie 2019;39:259-265.
}

\begin{abstract}
Address for correspondence Donald M. Arnold, MD, MSc, FRCP(C), Department of Medicine, McMaster University HSC 3H50, 1280 Main Street West, Hamilton, Ontario L8S4K1, Canada (e-mail: arnold@mcmaster.ca).
\end{abstract}

\begin{abstract}
Keywords

- platelet

- autoimmune diseases

- paediatric
\end{abstract}

Immune thrombocytopenia (ITP) is an autoimmune disease affecting blood platelets that causes thrombocytopenia and an increased risk of bleeding. First-line therapy is indicated for patients with bleeding complications or who are at increased risk of bleeding, and the decision to initiate therapy depends not only on the platelet count, but also on other endpoints including quality of life. The choice of first-line therapy depends primarily on how quickly a platelet count response is required, with intravenous immune globulin providing the more rapid response, followed by highdose dexamethasone and prednisone. In this narrative review, we discuss key issues with first-line therapy in ITP including when to initiate therapy, treatment options and special considerations for children. Evidence-based guidelines are lacking for the emergency management of patients with ITP who present with significant bleeding; we provide our approach to this critical situation.

\section{Introduction}

Immune thrombocytopenia (ITP), formerly immune thrombocytopenic purpura, is a disorder of platelet number characterized by thrombocytopenia and an increased risk of bleeding. The International Working Group defined primary ITP as a platelet count less than $100 \times 10^{9} / \mathrm{L}$ in the absence of other causes or underlying conditions. ${ }^{1,2}$ Although ITP is a heterogeneous syndrome with diverse pathological mechanisms, ${ }^{3,4}$ it remains a diagnosis of exclusion and misdiagnosis is common, even among experienced haematologists. ${ }^{5}$

Newly diagnosed patients with ITP who are at low risk of bleeding can be safely managed with observation, while those with severe thrombocytopenia or at higher risk of bleeding require urgent treatment. This review explores common questions about first-line therapy for ITP, including when to treat/when not to treat, efficacy and safety of firstline therapies, management of ITP bleeding emergencies and unique treatment considerations for paediatric patients.

\section{When to Treat/When Not to Treat ITP}

The platelet count is the most important measure of disease activity in patients with ITP. As a surrogate marker, the platelet

received

November 3, 2018

accepted after revision

February 14, 2019

count inversely correlates with morbidity from bleeding, ${ }^{6,7}$ but is only one of many factors that influence the bleeding risk of an individual patient. ${ }^{8}$ Patients with severe bleeding almost invariably have severe thrombocytopenia, but most patients with severe thrombocytopenia do not bleed.

Reported rates of severe bleeding vary depending on the population studied and the instrument used to measure bleeding. In a systematic review of 118 studies ( $n=10,908$ patients with ITP), the rate of intracranial haemorrhage (ICH) was $1.0 \%$ overall ( $95 \%$ confidence interval [CI]: $0.7-1.3$ ), $1.4 \%$ in adults ( $95 \% \mathrm{CI}: 0.9-2.1)$ and $0.4 \%$ in children ( $95 \% \mathrm{CI}: 0.2-$ $0.7){ }^{9}$ Among 29 studies that reported this outcome, the overall rate of non-ICH major bleeding was $15.0 \%$ (95\% CI: 4.1-17.1). ${ }^{9}$ A more recent study that measured bleeding prospectively using a validated ITP bleeding assessment tool $^{6}$ reported that $56 \%$ of patients had severe bleeding at some point during their disease course, and $2 \%$ had ICH. ${ }^{5}$

Deaths due to bleeding are rare, and overall mortality among patients with ITP is only slightly higher than age- and sex-matched controls. In a cohort study of 152 adults with ITP, the relative mortality risk was 1.5 (95\% CI: 1.1-2.2), which was not significantly higher than the general population after patients with secondary ITP were excluded

(c) 2019 Georg Thieme Verlag KG Stuttgart · New York
DOI https://doi.org/ $10.1055 / s-0039-1684031$. ISSN 0720-9355. 
(relative risk [RR]: 1.3; 95\% CI: 0.89-2.0). ${ }^{10}$ Biologically, patients with ITP tend to have less bleeding complications compared with patients with non-ITP and similar platelet counts (e.g. chemotherapy-induced thrombocytopenia) likely because in ITP, the platelets are generally 'younger' and more haemostatically active. ${ }^{11}$

Besides the platelet count and bleeding, health-related quality of life (HRQoL) and fatigue are other endpoints that should be considered when deciding on treatment. HRQoL has been shown to be reduced in patients with chronic ITP compared with matched controls, specifically in the domains of physical and mental wellbeing. ${ }^{12}$ Fatigue is reported in 20 to $40 \%$ of patients with ITP and has been associated with female sex and severe thrombocytopenia in one cross-sectional study $(n=653))^{13}$ Treatment with eltrombopag, ${ }^{14}$ romiplostim $^{15}$ and other therapies ${ }^{16}$ has been shown to improve HRQoL among adults and children.

The importance of the platelet count level in deciding on treatment depends on the population. For children, acute severe thrombocytopenia often resolves spontaneously and the toxicities of treatments often outweigh their benefits. ${ }^{1}$ For adults, severe thrombocytopenia is much less likely to improve spontaneously.$^{17}$ Furthermore, patients with additional bleeding risks (e.g. those who require anti-coagulation or anti-platelet agents), patients undergoing invasive procedures or patients at increased risk of trauma (e.g. contact sports) may need a higher platelet count threshold for treatment. $^{18}$ Treatment guidelines from the American Society of Hematology ${ }^{1}$ recommend treatment for adults with newly diagnosed ITP and a platelet count $<30 \times 10^{9} / \mathrm{L}$ (Grade 2C) since above $30 \times 10^{9} / \mathrm{L}$, clinically significant bleeding is rare. ${ }^{9}$ Recommendations for children place less emphasis on the platelet count number, and more emphasis on clinical evidence of haemostatic impairment. ${ }^{1}$

The decision to initiate treatment should be based on the platelet count level and other factors that influence the bleeding risk in individual patients. In addition, HRQoL and the toxicities of treatment are also important considerations. While estimating the bleeding risk of an individual patient is imprecise, predictors of bleeding include severe thrombocytopenia (defined as a platelet count $<10 \times 10^{9} / \mathrm{L}$ or $<20 \times 10^{9} / \mathrm{L}$ ), chronic ITP, history of major bleeding and older age ( $>60$ years). ${ }^{9}, 19$ A platelet count response to intravenous immune globulin (IVIG) or corticosteroids can be useful to differentiate ITP from other thrombocytopenic disorders. ${ }^{20}$ Most non-bleeding adults with ITP can be treated in the outpatient setting with close follow-up. Hospital admission should be considered for patients with newly diagnosed ITP and severe thrombocytopenia, or for patients at increased risk for bleeding (e.g. those who are taking an anti-coagulant ${ }^{7}$ ).

\section{Choice of First-Line Therapy for ITP}

ITP treatments are prescribed to achieve one of three main goals: (1) to rapidly but transiently raise the platelet count level; (2) to maintain a stable, haemostatic platelet count or (3) to achieve remission. ${ }^{4}$ Traditional first-line treatments with corticosteroids, IVIG or Rh(D) immune globulin (RhIg) are directed at the first goal of rapidly raising the platelet count. A more recent concept for first-line therapy is to consider the goal of achieving remission without the need for maintenance therapy, as has been recently reported in a subgroup of patients who received thrombopoietin (TPO) receptor agonist (TPO-RA) medications. ${ }^{21,22}$ While previous reports had suggested that high-dose corticosteroids ${ }^{23}$ or IVIG ${ }^{24}$ may improve long-term disease control, more recent studies have found that neither improves response rates at 6 months. ${ }^{25,26}$

Guidelines from the American Society of Hematology ${ }^{1}$ recommend corticosteroids, IVIG or RhIg as first-line therapy for a newly diagnosed adult with ITP. The urgency of a platelet count response, and the patient's comorbidities and preferences should guide which treatment should be prescribed. The fastest platelet count responses can be achieved with IVIG (1248 hours), followed by high-dose dexamethasone (1-2 days) and standard-dose prednisone (2-4 days) ${ }^{2,27}$ Thus IVIG (or $\mathrm{RhIg}$ ) is preferred when a rapid rise in the platelet count is required. Concerns about toxicities with RhIg have limited its use in recent years (see below).

\section{Corticosteroids}

Commonly prescribed corticosteroid regimens include highdose dexamethasone and standard-dose prednisone. Dexamethasone is most commonly administered as one or more cycles of $40 \mathrm{mg}$ orally once daily for 4 days, with no taper usually 4 weeks apart. ${ }^{28}$ Prednisone is administered 1 to 2 $\mathrm{mg} / \mathrm{kg}$ orally per day for 1 to 2 weeks, with a gradual taper and discontinuation by 6 to 8 weeks. ${ }^{26}$ Lower starting doses of prednisone may also be effective. ${ }^{29,30}$ As in other autoimmune diseases, ${ }^{31}$ there is no evidence supporting a specific corticosteroid tapering regimen in ITP. Up to $80 \%$ of patients with ITP will have an initial response to corticosteroids $^{26}$; however, long-term responses are less common and have been observed in only 20 to $40 \%$ of newly diagnosed patients, ${ }^{26,28}$ which may be related to the treatment or to the natural history of the disease. In a meta-analysis of five randomized trials ( $n=533$ patients), high-dose dexamethasone increased the likelihood of a platelet count response by day 14 (79 vs. 59\%; RR: 1.22 ; 95\% CI: $1.00-1.49$ ) when compared with standard-dose prednisone, but did not lead to more long-term remissions. ${ }^{26}$

Corticosteroids should be tapered rapidly and discontinued in non-responding patients. Short courses of dexamethasone (which has an anti-inflammatory effect that is 7.5 times more potent than prednisone $)^{32}$ may prevent toxicities associated with prolonged corticosteroid exposure, including weight gain and osteoporosis, but result in acute toxicities including cognitive impairments, hypertension and hyperglycaemia. Notably, most studies of high-dose dexamethasone in ITP excluded patients with uncontrolled diabetes, hypertension or cardiovascular disease. ${ }^{23,33}$

\section{Intravenous Immune Globulin}

IVIG is usually administered as 1 to $2 \mathrm{~g} / \mathrm{kg}$ in divided doses. Treatment guidelines from the American Society of Hematology ${ }^{1}$ recommend that IVIG should be given initially as a single dose of $1 \mathrm{~g} / \mathrm{kg}$ and repeated in non-responding patients. In a 
randomized trial of 37 adults with ITP and a platelet count $<50 \times 10^{9} / \mathrm{L}$, patients who received a single IVIG dose of $1 \mathrm{~g} / \mathrm{kg}$ were more likely to have a platelet count response by day 4 compared with patients who received lower initial doses of 0.5 $\mathrm{g} / \mathrm{kg}(67 \mathrm{vs.} 21 \%, p=0.005) .{ }^{34}$ Patients who had no response by day 4 received a second dose of IVIG (either 1.5 or $1 \mathrm{~g} / \mathrm{kg}$ depending on the initial dose given), which resulted in an excellent cumulative response rate of $78 \%$ that was similar between groups. These results suggest that an initial IVIG dose of $1 \mathrm{~g} / \mathrm{kg}$ is preferred for most patients with the possibility of repeating a second dose the next day. Common side effects of IVIG include headache in 10 to $25 \%$ of patients, ${ }^{35}$ aseptic meningitis ${ }^{36}$ and acute kidney injury. ${ }^{37,38}$ Haemolysis from passive transfer of anti-A and anti-B haemagglutinins is an uncommon complication that can occur in non-blood group $\mathrm{O}$ patients, with IVIG preparations containing high-titre anti-A or anti-B antibodies and large cumulative doses of IVIG (>100 g over $2-4$ days) ${ }^{39}$

IVIG has been associated with an increased risk of thrombosis, which led to a boxed warning from the U.S. Food and Drug Administration in $2013 .{ }^{40}$ The risk has been estimated at $1 \%$ per year for arterial or venous thrombosis for patients who are regularly treated with IVIG. ${ }^{41,42}$ Risk estimates vary depending on a patient's underlying risk factors for thromboembolism, the specific product used and the indication for treatment. In contrast to the findings of observational studies, a recent systematic review of 31 randomized trials ( $n=4,129$ patients) did not demonstrate an increased risk of thromboembolism with IVIG for a variety of indications (odds ratio [OR]: 1.10; 95\% CI: 0.44-2.88). ${ }^{43}$

IVIG raises the platelet count more rapidly than corticosteroids. ${ }^{44}$ In a multicentre, randomized $2 \times 2$ trial of 122 adults with newly diagnosed ITP $^{27}$ and a platelet count $\leq 20 \times 10^{9} / \mathrm{L}$, patients were randomized to IVIG at a dose of $0.7 \mathrm{~g} / \mathrm{kg}$ daily for 3 days or high-dose methylprednisolone at a dose of $15 \mathrm{mg} / \mathrm{kg}$ daily for 3 days (first randomization). Patients then received either oral prednisone $(1 \mathrm{mg} / \mathrm{kg}$ per day) or placebo from days 4 to 21 (second randomization). IVIG was more effective at raising the platelet count by day 5 than corticosteroids ( 79 vs. $60 \%$ response rate, $p=0.04$ ). Long-term responses were similar between patients who initially received IVIG or methylprednisolone ( 64 vs. $60 \%, p=0.80$ ). In total, $24 \%$ of the patients experienced transient, mostly mild, side effects from therapy and there were no deaths.

\section{Rh(D) Immune Globulin}

The mechanism of action of RhIg is to bind and occupy Fc receptors in the reticuloendothelial system with antibodycoated $\mathrm{Rh}(\mathrm{D})$-positive red blood cells, thus preventing antibody-coated platelets from being destroyed. ${ }^{45} \mathrm{RhIg}$ is usually given at a dose of 50 to $75 \mathrm{mcg} / \mathrm{kg}$ intravenously ${ }^{46}$ and is reserved for patients with $\mathrm{Rh}(\mathrm{D})$-positive blood type with an intact spleen. RhIg can cause mild infusion reactions such as headache, nausea, chills, fever and mild to moderate haemolysis. ${ }^{47}$ Life-threatening episodes of severe intravascular haemolysis associated with RhIg administration have been rarely reported. ${ }^{48,49}$ These observations led to a warning on the product monograph ${ }^{50}$ and withdrawal from European markets.

\section{Can Some First-Line Therapies Induce Long- Term Remission?}

Several early observational studies showed encouraging effects of high-dose dexamethasone on rates of long-term remission in adults, with studies reporting 6-month response rates between 40 and $80 \%{ }^{23,51}$ Randomized trials, however, did not show a difference in long-term benefits with high-dose dexamethasone or prednisone, as demonstrated in a recent meta-analysis ( $n=533$ patients). ${ }^{26}$ Rates of long-term responses at 6 months were $54 \%$ with high-dose dexamethasone and $43 \%$ with prednisone $(p=0.44)$; however, $79 \%$ of patients in the dexamethasone group achieved a platelet count response at 14 days compared with $59 \%$ of patients in the prednisone group (RR: $1.22 ; 95 \% \mathrm{CI}: 1.00-$ $1.49 ; p=0.048$ ).

Early use of IVIG in children was initially thought to reduce the risk of chronic ITP. ${ }^{24,44}$ In a systematic review of nine randomized trials ( $n=596$ patients) comparing IVIG with corticosteroids in children with newly diagnosed ITP, $25 \%$ of children treated with corticosteroids and $18 \%$ of children treated with IVIG went on to develop chronic ITP $(p=0.04) \cdot{ }^{44}$ A case-control study of 449 matched pairs of children with ITP showed that patients who received IVIG were more likely to have a normal platelet count 6 months after diagnosis than patients who did not receive IVIG (OR: 1.81; $95 \%$ CI: $1.25-2.64) .{ }^{24}$ In contrast, a recent randomized trial did not show a difference in long-term benefit with IVIG compared with observation alone in children with ITP, although there was a trend towards improved disease control at 6 months. ${ }^{25}$ In this trial, 206 children (aged 3 months to 16 years) with newly diagnosed ITP, platelets $<20 \times 10^{9} / \mathrm{L}$ and mild to moderate bleeding were randomized to receive either a single dose of IVIG $0.8 \mathrm{~g} / \mathrm{kg}$ or observation. Chronic ITP occurred in $18.6 \%$ of patients in the IVIG arm compared with $28.9 \%$ in the observation arm (RR: 0.64; 95\% CI: 0.38-1.08).

Treatment intensification in the first-line setting is hypothesized to increase the likelihood of achieving long-term disease remission. ${ }^{3}$ Two randomized trials of rituximab showed a higher rate of sustained platelet count response at 6 months (58-63\%) compared with standard of care.52,53 Two other placebo-controlled trials, one in newly diagnosed or relapsed patients $^{54}$ and one in corticosteroid-unresponsive patients ${ }^{55}$ showed no difference in response rates at 6 months or longer. A meta-analysis of non-splenectomized patients $(n=463)$ showed slightly higher rates of complete response with rituximab (47\% vs. 33\%; RR: 1.42 ; 95\% CI: $1.13-1.77 ; p=0.0020$ ). ${ }^{56}$ Two-single arm studies have evaluated the use of TPO-RAs in the first-line setting ${ }^{21,22}$ based on observational studies that reported remission rates of up to $30 \%$ after drug discontinuation. ${ }^{57}$ In one study, romiplostim was given to 75 adults with newly diagnosed ITP to target a platelet count of $50-200 \times 10^{9} /$ L. ${ }^{22}$ At the end of 12 months, patients with a platelet count above $50 \times 10^{9} / \mathrm{L}$ gradually tapered and discontinued romiplostim. Twenty-four patients (32\%) had long-term disease remission. In another study, 12 adults received a 4-day course of high-dose dexamethasone followed by a 28-day course of eltrombopag (50 mg orally daily). ${ }^{21}$ Nine patients (75\%) had a 
platelet count $\geq 30 \times 10^{9} / \mathrm{L}$ at 6 months and eight patients (67\%) had a response at 12 months off therapy. These encouraging data require further confirmation.

\section{Management of ITP Bleeding Emergencies}

Severe bleeding in ITP is a rare, life-threatening medical emergency. Goals of treatment are to increase the platelet count to a safe level and to stop the bleeding. This requires a multipronged approach that includes medications, blood transfusions and coordination with other clinical services for appropriate interventions (e.g. endoscopy, neurosurgery, etc.). There are currently no evidence-based guidelines for ITP bleeding emergencies, thus treatment recommendations reflect expert opinion. ${ }^{1}$ In our opinion, an ITP bleeding emergency should be considered in a patient with presumed or definite ITP who has a platelet count $<20 \times 10^{9} / \mathrm{L}$ and significant bleeding including $\mathrm{ICH}$, pulmonary haemorrhage, abnormal vaginal bleeding, macroscopic haematuria, overt gastrointestinal bleeding and perhaps extensive mucosal purpura. $^{6,7}$ This definition is based on the ITP-bleeding score $^{6}$ and incorporates criteria for severe bleeding that is beyond skin bruising or petechiae. ${ }^{7}$

Treatment of acute bleeding in adults and children, especially ICH, is highly time-sensitive. Early haematoma growth, the principal cause of neurological deterioration after $\mathrm{ICH}$, occurs in up to $40 \%$ of patients within 3 hours of ICH onset and predicts 30 -day mortality. ${ }^{58}$ Similarly, upper gastrointestinal bleeding should be treated with early endoscopy ( $<24$ hours) ${ }^{59}$ Our practice is to treat patients with severe thrombocytopenia (platelet count $<20 \times 10^{9} / \mathrm{L}$ ) and limb or life-threatening bleeding with combination therapy that includes corticosteroids, IVIG and platelet transfusions. ${ }^{1,60,61}$ High-dose dexamethasone (e.g. $40 \mathrm{mg}$ daily for 4 days) and high-dose methylprednisolone (e.g. $1 \mathrm{~g}$ intravenously daily for 3 days) increase the platelet count faster than standard-dose prednisone. ${ }^{26}$ Platelet transfusions cause a rapid but temporary increase in platelet count and may be effective at reducing bleeding even in the absence of a platelet count rise. IVIG may also lengthen the lifespan of transfused platelets. ${ }^{62}$ Urgent use of TPO-RAs, such as romiplostim, may be sensible but requires further study. These agents would only be expected to work after 1 to 2 weeks with the goal of avoiding severe thrombocytopenia recurrence after initial disease control. ${ }^{60}$ Tranexamic acid, recombinant factor VIIa, intravenous vincristine (1-2 mg) or RhIg (75 $\mu \mathrm{g} / \mathrm{kg}$ ) may be useful adjunctive treatments for severe, refractory bleeding. ${ }^{1,61}$ Refractory bleeding may require emergency splenectomy. ${ }^{1}$ Patients with bleeding emergencies should be hospitalized until bleeding is controlled. On discharge, close outpatient follow-up should be arranged because responses to urgent treatments may be short-lived.

\section{First-Line Therapy for Children}

Most children with ITP are asymptomatic at diagnosis or present with bleeding confined to the skin or oral mucosa. ${ }^{63}$ Whether or not to treat such patients depends on the degree of thrombocytopenia, the severity of bleeding and the presence of other risk factors for bleeding. ${ }^{1,18}$ Evidence-based treatment guidelines from the American Society of Hematology ${ }^{1}$ recommend that children with no bleeding or mild bleeding only (defined as skin bruising or petechiae) be managed with observation alone, regardless of the platelet count (Grade 1B). ${ }^{1}$ This strategy is more conservative than in adults because (1) most children with newly diagnosed ITP will remit spontaneously within 3 to 6 months ${ }^{64,65}$; (2) front-line therapies (corticosteroids, IVIG) do not appear to influence rates of longterm disease remission ${ }^{25}$ and (3) severe bleeding is rare, occurring in only $3 \%$ of children at diagnosis. ${ }^{65,66} \mathrm{ICH}$ is especially rare in children: $0.4 \%$ compared with $1.4 \%$ in adults. ${ }^{9}$ A variety of corticosteroid dosing regimens have been used in children, including prednisone at a dose of 1 to $2 \mathrm{mg} / \mathrm{kg} /$ day or short courses of high-dose dexamethasone $\left(24 \mathrm{mg} / \mathrm{m}^{2} /\right.$ day, maximum $40 \mathrm{mg}$ per day, for 4 days with no taper). There is insufficient evidence to support any one corticosteroid dosing strategy over another. ${ }^{1}$ IVIG is typically administered as a single dose of 0.8 to $1 \mathrm{~g} / \mathrm{kg}^{1}$

\section{First-Line Therapy in Pregnancy}

Indications for treatment of ITP in pregnancy are similar to those in non-pregnant patients. Treatment is indicated for bleeding patients, and should be considered if the platelet count falls below $20-30 \times 10^{9} / \mathrm{L}$. First-line therapies are corticosteroids and IVIG. We prefer prednisone, given at a dose of 0.5 to $1 \mathrm{mg} / \mathrm{kg}$ daily for 7 to 14 days, over dexamethasone, which is a synthetic, fluorinated corticosteroid that crosses the placenta. ${ }^{67,68} \mathrm{~A}$ retrospective review compared IVIG and corticosteroids as initial therapy for 91 pregnant ITP patients and showed no differences in maternal outcomes including platelet count responses. ${ }^{69}$ Therefore, choosing between corticosteroids and IVIG should depend on the toxicities of treatment and how rapidly a response is needed. IVIG raises the platelet count faster than corticosteroids and may be preferred if delivery is imminent. Corticosteroids are more convenient and inexpensive, but may exacerbate post-partum psychiatric disorders, gestational hypertension and diabetes. ${ }^{1,70}$ The safety of rituximab and TPO-RAs in pregnancy is not well established and their use is generally avoided. ${ }^{71,72}$ The mode of delivery should be based on obstetrical indications. ${ }^{1}$ Recommended platelet count thresholds at delivery are $30 \times 10^{9} / \mathrm{L}$ for vaginal delivery, $50 \times 10^{9} / \mathrm{L}$ for cesarean delivery and $80-100 \times 10^{9} / \mathrm{L}$ for epidural catheter insertion. The infant's platelet count should be monitored in the first week after delivery, since approximately $10 \%$ of infants born to mothers with ITP will have thrombocytopenia. ${ }^{73}$

\section{Recommendations for First-Line ITP Therapy}

Although the platelet count is the single most important marker for disease activity in ITP, the decision to initiate therapy should be individualized and take into account patient preferences and risk factors for bleeding. In an asymptomatic adult with ITP, treatment should be considered if the platelet 
Table 1 Summary of first-line ITP therapy including when to start, which treatment to use, and how to manage ITP bleeding emergencies

\begin{tabular}{|c|l|}
\hline When to start first-line therapy? & $\begin{array}{l}\text { Adults: severe thrombocytopenia }<20-30 \times 10^{9} / \mathrm{L} \text {, adjust threshold based on indi- } \\
\text { vidual risk factors for bleeding. } \\
\text { Children: platelets }<20-30 \times 10^{9} / \mathrm{L} \text { and significant bleeding that is worse than skin } \\
\text { bruising or petechiae. }\end{array}$ \\
\hline Which first-line therapy should be used? \\
\hline \multicolumn{1}{|c|}{ Corticosteroids } & $\begin{array}{l}\text { High-dose dexamethasone }(40 \mathrm{mg} \text { orally for } 4 \text { days, with no taper) or standard dose } \\
\text { prednisone }(1-2 \mathrm{mg} / \mathrm{kg} \text { daily for } 1-2 \text { weeks with gradual tapering). Time to response is } \\
\text { faster with high-dose dexamethasone. }\end{array}$ \\
\hline IVIG & $\begin{array}{l}\text { Single dose of } 1 \mathrm{~g} / \mathrm{kg} \text { and repeated the following day in non-responding patients. } \\
\text { Expected time to response is } 12-24 \text { h. IVIG should be used to treat patients with } \\
\text { bleeding or when a rapid platelet count response is required. }\end{array}$ \\
\hline Other treatments & $\begin{array}{l}\text { Rituximab: early use of rituximab in combination with high-dose dexamethasone } \\
\text { improves long-term remission rates, but with increased risk of grade } 3-4 \text { toxicities. } \\
\text { TPO-RAs: observational studies suggest increased rates of remission with early use of } \\
\text { TPO-RAs. }\end{array}$ \\
\hline $\begin{array}{l}\text { Managing an ITP bleeding } \\
\text { emergency }\end{array}$ & $\begin{array}{l}\text { Patients require hospitalization and combination therapy with high-dose corticoster- } \\
\text { oids, IVIG and platelet transfusions. Adjunctive treatments may include recombinant } \\
\text { factor VIla, tranexamic acid, and TPO-RAs. }\end{array}$ \\
\hline
\end{tabular}

Abbreviation: ITP, Immune thrombocytopenia; IVIG, intravenous immune globulin; TPO-RAs, thrombopoietin-receptor agonists.

count falls below $20-30 \times 10^{9} / \mathrm{L}$. $^{1}$ Most children with ITP and no bleeding should be managed by observation alone. ${ }^{1}$ Treatment should be given with an aim to rapidly raise the platelet count, maintain a stable platelet count or to achieve long-term disease remission. ${ }^{4}$ We do not routinely use ITP therapies to alleviate fatigue, or improve physical or mental wellbeing in the absence of another indication for therapy.

Our approach to fist-line therapy is summarized in -Table 1. We prefer high-dose dexamethasone $(40 \mathrm{mg}$ orally for 4 days with no taper) over standard-dose prednisone because it leads to a faster platelet count response and avoids toxicities associated with prolonged courses of glucocorticoids. ${ }^{26}$ If there is no platelet count response, we reevaluate whether ITP is the most likely diagnosis and consider alternate treatments such as IVIG. IVIG is indicated when a rapid platelet count response is required and should be administered as a single dose of $1 \mathrm{~g} / \mathrm{kg}$, and repeated if the platelet count does not respond by day 2 . Some evidence suggests that early use of TPO-RAs can increase the likelihood of long-term disease remission, but this requires further confirmation. ${ }^{21,22}$ ITP bleeding emergencies should be managed with the combination of high-dose corticosteroids, IVIG and platelet transfusions. ${ }^{61}$ Adjunctive treatments in an emergency setting may include tranexamic acid, TPORAs and recombinant factor VIIa.

Conflict of Interest

None.

\section{References}

1 Neunert C, Lim W, Crowther M, Cohen A, Solberg L Jr, Crowther MA; American Society of Hematology. The American Society of Hematology 2011 evidence-based practice guideline for immune thrombocytopenia. Blood 2011;117(16):4190-4207
2 Rodeghiero F, Stasi R, Gernsheimer T, et al. Standardization of terminology, definitions and outcome criteria in immune thrombocytopenic purpura of adults and children: report from an international working group. Blood 2009;113(11):2386-2393

3 Lambert MP, Gernsheimer TB. Clinical updates in adult immune thrombocytopenia. Blood 2017;129(21):2829-2835

4 Toltl LJ, Arnold DM. Pathophysiology and management of chronic immune thrombocytopenia: focusing on what matters. $\mathrm{Br} \mathrm{J}$ Haematol 2011;152(01):52-60

5 Arnold DM, Nazy I, Clare R, et al. Misdiagnosis of primary immune thrombocytopenia and frequency of bleeding: lessons from the McMaster ITP Registry. Blood Adv 2017;1(25):2414-2420

6 Page LK, Psaila B, Provan D, et al. The immune thrombocytopenic purpura (ITP) bleeding score: assessment of bleeding in patients with ITP. Br J Haematol 2007;138(02):245-248

7 Piel-Julian ML, Mahévas M, Germain J, et al; CARMEN investigators group. Risk factors for bleeding, including platelet count threshold, in newly diagnosed immune thrombocytopenia adults. J Thromb Haemost 2018;16(09):1830-1842

8 Arnold DM, Lim W. A rational approach to the diagnosis and management of thrombocytopenia in the hospitalized patient. Semin Hematol 2011;48(04):251-258

9 Neunert C, Noroozi N, Norman G, et al. Severe bleeding events in adults and children with primary immune thrombocytopenia: a systematic review. J Thromb Haemost 2015;13(03):457-464

10 Portielje JE, Westendorp RG, Kluin-Nelemans HC, Brand A. Morbidity and mortality in adults with idiopathic thrombocytopenic purpura. Blood 2001;97(09):2549-2554

11 Peng J, Friese P, Heilmann E, George JN, Burstein SA, Dale GL. Aged platelets have an impaired response to thrombin as quantitated by P-selectin expression. Blood 1994;83(01):161-166

12 McMillan R, Bussel JB, George JN, Lalla D, Nichol JL. Self-reported health-related quality of life in adults with chronic immune thrombocytopenic purpura. Am J Hematol 2008;83(02):150-154

13 Newton JL, Reese JA, Watson SI, et al. Fatigue in adult patients with primary immune thrombocytopenia. Eur J Haematol 2011;86 (05):420-429

14 Khelif A, Saleh MN, Salama A, et al. Patient-reported healthrelated quality of life improves over time in patients with chronic immune thrombocytopenia receiving long-term treatment with eltrombopag. Blood 2016;128(22):3750 
15 George JN, Mathias SD, Go RS, et al. Improved quality of life for romiplostim-treated patients with chronic immune thrombocytopenic purpura: results from two randomized, placebo-controlled trials. Br J Haematol 2009;144(03):409-415

16 Grace RF, Klaassen RJ, Bhat R, et al. Health related quality of life and fatigue improve on second line treatments in pediatric immune thrombocytopenia (ITP). Blood 2017;130(Suppl 1):752

17 Stasi R, Stipa E, Masi M, et al. Long-term observation of 208 adults with chronic idiopathic thrombocytopenic purpura. Am J Med 1995;98(05):436-442

18 Grace RF, Despotovic JM, Bennett CM, et al. Physician decision making in selection of second-line treatments in immune thrombocytopenia in children. Am J Hematol 2018;93(07):882-888

19 Cortelazzo S, Finazzi G, Buelli M, Molteni A, Viero P, Barbui T. High risk of severe bleeding in aged patients with chronic idiopathic thrombocytopenic purpura. Blood 1991;77(01):31-33

20 Salib M, Clayden R, Clare R, et al. Difficulties in establishing the diagnosis of immune thrombocytopenia: an agreement study. Am J Hematol 2016;91(08):E327-E329

21 Gómez-Almaguer D, Herrera-Rojas MA, Jaime-Pérez JC, et al. Eltrombopag and high-dose dexamethasone as frontline treatment of newly diagnosed immune thrombocytopenia in adults. Blood 2014;123(25):3906-3908

22 Newland A, Godeau B, Priego V, et al. Remission and platelet responses with romiplostim in primary immune thrombocytopenia: final results from a phase 2 study. Br J Haematol 2016;172 (02):262-273

23 Cheng Y, Wong RSM, Soo YOY, et al. Initial treatment of immune thrombocytopenic purpura with high-dose dexamethasone. N Engl J Med 2003;349(09):831-836

24 Tamminga R, Berchtold W, Bruin M, Buchanan GR, Kühne T. Possible lower rate of chronic ITP after IVIG for acute childhood ITP an analysis from registry I of the Intercontinental Cooperative ITP Study Group (ICIS). Br J Haematol 2009;146(02):180-184

25 Heitink-Pollé KMJ, Uiterwaal CSPM, Porcelijn L, et al; TIKI Investigators. Intravenous immunoglobulin vs observation in childhood immune thrombocytopenia: a randomized controlled trial. Blood 2018;132(09):883-891

26 Mithoowani S, Gregory-Miller K, Goy J, et al. High-dose dexamethasone compared with prednisone for previously untreated primary immune thrombocytopenia: a systematic review and meta-analysis. Lancet Haematol 2016;3(10):e489-e496

27 Godeau B, Chevret S, Varet B, et al; French ATIP Study Group. Intravenous immunoglobulin or high-dose methylprednisolone, with or without oral prednisone, for adults with untreated severe autoimmune thrombocytopenic purpura: a randomised, multicentre trial. Lancet 2002;359(9300):23-29

28 Cuker A, Prak ET, Cines DB. Can immune thrombocytopenia be cured with medical therapy? Semin Thromb Hemost 2015;41 (04):395-404

29 Bellucci S, Charpak Y, Chastang C, Tobelem G. Low doses v conventional doses of corticoids in immune thrombocytopenic purpura (ITP): results of a randomized clinical trial in 160 children, 223 adults. Blood 1988;71(04):1165-1169

30 Mazzucconi MG, Francesconi M, Fidani P, et al. Treatment of idiopathic thrombocytopenic purpura (ITP): results of a multicentric protocol. Haematologica 1985;70(04):329-336

31 Hoes JN, Jacobs JW, Boers M, et al. EULAR evidence-based recommendations on the management of systemic glucocorticoid therapy in rheumatic diseases. Ann Rheum Dis 2007;66 (12):1560-1567

32 Brunton L, Lazo J, Parker K. Goodman \& Gilman's The Pharmacological Basis of Therapeutics. 11th ed. New York, NY: McGraw-Hill Education; 2005

33 Wei Y, Ji XB, Wang YW, et al. High-dose dexamethasone versus prednisone for treatment of adult immune thrombocytopenia: a prospective multicenter randomized trial. Blood 2016;127(03): 296-302, quiz 370
34 Godeau B, Caulier MT, Decuypere L, Rose C, Schaeffer A, Bierling P. Intravenous immunoglobulin for adults with autoimmune thrombocytopenic purpura: results of a randomized trial comparing 0.5 and $1 \mathrm{~g} / \mathrm{kg}$ b.w. Br J Haematol 1999;107(04):716-719

35 Singh-Grewal D, Kemp A, Wong M. A prospective study of the immediate and delayed adverse events following intravenous immunoglobulin infusions. Arch Dis Child 2006;91(08):651-654

36 Sekul EA, Cupler EJ, Dalakas MC. Aseptic meningitis associated with high-dose intravenous immunoglobulin therapy: frequency and risk factors. Ann Intern Med 1994;121(04):259-262

37 Ahsan N. Intravenous immunoglobulin induced-nephropathy: a complication of IVIG therapy. J Nephrol 1998;11(03):157-161

38 Donga PZ, Bilir SP, Little G, Babinchak T, Munakata J. Comparative treatment-related adverse event cost burden in immune thrombocytopenic purpura. J Med Econ 2017;20(11):1200-1206

39 Padmore RF. Hemolysis upon intravenous immunoglobulin transfusion. Transfus Apheresis Sci 2012;46(01):93-96

40 FDA Safety Communication: New boxed warning for thrombosis related to human immune globulin products: Food and Drug Administration; 2013

41 Ammann EM, Jones MP, Link BK, et al. Intravenous immune globulin and thromboembolic adverse events in patients with hematologic malignancy. Blood 2016;127(02):200-207

42 Daniel GW, Menis M, Sridhar G, et al. Immune globulins and thrombotic adverse events as recorded in a large administrative database in 2008 through 2010. Transfusion 2012;52(10): 2113-2121

43 Ammann EM, Haskins CB, Fillman KM, et al. Intravenous immune globulin and thromboembolic adverse events: a systematic review and meta-analysis of RCTs. Am J Hematol 2016;91(06): 594-605

44 Beck CE, Nathan PC, Parkin PC, Blanchette VS, Macarthur C. Corticosteroids versus intravenous immune globulin for the treatment of acute immune thrombocytopenic purpura in children: a systematic review and meta-analysis of randomized controlled trials. J Pediatr 2005;147(04):521-527

45 Bussel JB, Graziano JN, Kimberly RP, Pahwa S, Aledort LM. Intravenous anti-D treatment of immune thrombocytopenic purpura: analysis of efficacy, toxicity, and mechanism of effect. Blood 1991; 77(09):1884-1893

46 Newman GC, Novoa MV, Fodero EM, Lesser ML, Woloski BM, Bussel JB. A dose of $75 \mathrm{microg} / \mathrm{kg} / \mathrm{d}$ of i.v. anti-D increases the platelet count more rapidly and for a longer period of time than 50 microg/kg/d in adults with immune thrombocytopenic purpura. Br J Haematol 2001;112(04):1076-1078

47 Scaradavou A, Woo B, Woloski BM, et al. Intravenous anti-D treatment of immune thrombocytopenic purpura: experience in 272 patients. Blood 1997;89(08):2689-2700

48 Gaines AR. Disseminated intravascular coagulation associated with acute hemoglobinemia or hemoglobinuria following $\mathrm{Rh}(0)$ (D) immune globulin intravenous administration for immune thrombocytopenic purpura. Blood 2005;106(05):1532-1537

49 Tarantino MD, Bussel JB, Cines DB, et al. A closer look at intravascular hemolysis (IVH) following intravenous anti-D for immune thrombocytopenic purpura (ITP). Blood 2007;109(12): 5527, author reply 5528

50 Aptevo BioTherapeutics LLC. Product monograph: Rh(D) immune globulin (human) for injection. Available at: https://winrho.com/ pdfs/WinRho_CDN_PM_English_Aptevo_approved_May_2016.pdf. Accessed March 12, 2019

51 Mazzucconi MG, Fazi P, Bernasconi S, et al; Gruppo Italiano Malattie EMatologiche dell'Adulto (GIMEMA) Thrombocytopenia Working Party. Therapy with high-dose dexamethasone (HDDXM) in previously untreated patients affected by idiopathic thrombocytopenic purpura: a GIMEMA experience. Blood 2007; 109(04):1401-1407

52 Gudbrandsdottir S, Birgens HS, Frederiksen H, et al. Rituximab and dexamethasone vs dexamethasone monotherapy in newly 
diagnosed patients with primary immune thrombocytopenia. Blood 2013;121(11):1976-1981

53 Zaja F, Baccarani M, Mazza P, et al. Dexamethasone plus rituximab yields higher sustained response rates than dexamethasone monotherapy in adults with primary immune thrombocytopenia. Blood 2010;115(14):2755-2762

54 Arnold DM, Heddle NM, Carruthers J, et al. A pilot randomized trial of adjuvant rituximab or placebo for nonsplenectomized patients with immune thrombocytopenia. Blood 2012;119(06): 1356-1362

55 Ghanima W, Khelif A, Waage A, et al; RITP study group. Rituximab as second-line treatment for adult immune thrombocytopenia (the RITP trial): a multicentre, randomised, double-blind, placebo-controlled trial. Lancet 2015;385(9978):1653-1661

56 Chugh S, Darvish-Kazem S, Lim W, et al. Rituximab plus standard of care for treatment of primary immune thrombocytopenia: a systematic review and meta-analysis. Lancet Haematol 2015;2 (02):e75-e81

57 Ghadaki B, Nazi I, Kelton JG, Arnold DM. Sustained remissions of immune thrombocytopenia associated with the use of thrombopoietin receptor agonists. Transfusion 2013;53(11):2807-2812

58 Mayer SA. Intracerebral hemorrhage: natural history and rationale of ultra-early hemostatic therapy. Intensive Care Med 2002; 28(Suppl 2):S235-S240

59 Barkun AN, Bardou M, Kuipers EJ, et al; International Consensus Upper Gastrointestinal Bleeding Conference Group. International consensus recommendations on the management of patients with nonvariceal upper gastrointestinal bleeding. Ann Intern Med 2010;152(02):101-113

60 Arnold DM. Bleeding complications in immune thrombocytopenia. Hematology (Am Soc Hematol Educ Program) 2015;2015:237-242

61 Cines DB, Bussel JB. How I treat idiopathic thrombocytopenic purpura (ITP). Blood 2005;106(07):2244-2251

62 Baumann MA, Menitove JE, Aster RH, Anderson T. Urgent treatment of idiopathic thrombocytopenic purpura with single-dose gammaglobulin infusion followed by platelet transfusion. Ann Intern Med 1986;104(06):808-809

63 Kühne T, Berchtold W, Michaels LA, et al; Intercontinental Cooperative ITP Study Group. Newly diagnosed immune thrombocy- topenia in children and adults: a comparative prospective observational registry of the Intercontinental Cooperative Immune Thrombocytopenia Study Group. Haematologica 2011; 96(12):1831-1837

64 Kühne T, Buchanan GR, Zimmerman S, et al; Intercontinental Childhood ITP Study Group; Intercontinental Childhood ITP Study Group. A prospective comparative study of 2540 infants and children with newly diagnosed idiopathic thrombocytopenic purpura (ITP) from the Intercontinental Childhood ITP Study Group. J Pediatr 2003;143(05):605-608

65 Rosthøj S, Hedlund-Treutiger I, Rajantie J, et al; NOPHO ITP Working Group. Duration and morbidity of newly diagnosed idiopathic thrombocytopenic purpura in children: a prospective Nordic study of an unselected cohort. J Pediatr 2003;143(03): 302-307

66 Neunert CE, Buchanan GR, Imbach P, et al; Intercontinental Childhood ITP Study Group Registry II Participants. Severe hemorrhage in children with newly diagnosed immune thrombocytopenic purpura. Blood 2008;112(10):4003-4008

67 Mok CC, Wong RW. Pregnancy in systemic lupus erythematosus. Postgrad Med J 2001;77(905):157-165

68 Kemp MW, Newnham JP, Challis JG, Jobe AH, Stock SJ. The clinical use of corticosteroids in pregnancy. Hum Reprod Update 2016;22 (02):240-259

69 Sun D, Shehata N, Ye XY, et al. Corticosteroids compared with intravenous immunoglobulin for the treatment of immune thrombocytopenia in pregnancy. Blood 2016;128(10):1329-1335

70 Yildirim Y, Tinar S, Oner RS, Kaya B, Toz E. Gestational diabetes mellitus in patients receiving long-term corticosteroid therapy during pregnancy. J Perinat Med 2006;34(04):280-284

71 Chakravarty EF, Murray ER, Kelman A, Farmer P. Pregnancy outcomes after maternal exposure to rituximab. Blood 2011;117 (05):1499-1506

72 Imbach P, Crowther M. Thrombopoietin-receptor agonists for primary immune thrombocytopenia. N Engl J Med 2011;365 (08):734-741

73 Webert KE, Mittal R, Sigouin C, Heddle NM, Kelton JG. A retrospective 11-year analysis of obstetric patients with idiopathic thrombocytopenic purpura. Blood 2003;102(13):4306-4311 